\title{
Foreword to the special issue: the European project UPStrat-MAFA
}

\section{Urban disaster prevention strategies using MAcroseismic Fields and FAult Sources}

\author{
Ragnar Sigbjörnsson ${ }^{1} \cdot$ Gaetano Zonno $^{2} \cdot$ Carlos Sousa Oliveira $^{3}$
}

Received: 27 April 2016/Accepted: 28 April 2016/Published online: 6 June 2016

(C) Springer Science+Business Media Dordrecht 2016

The special issue of Bulletin of Earthquake Engineering entitled UPStrat-MAFA (Urban Disaster Prevention Strategies using MAcroseismic and FAult Sources) is aimed to draw a picture on the main findings by a project devoted to seismic hazard, risk assessment, and disaster prevention in urban areas. The project, funded by the European Commission (http://upstrat-mafa.ov.ingv.it/UPStrat/), implemented strategies to prevent disasters built on the level of risk and on education information systems.

The use of macroseismic intensity to parameterize earthquakes effects allows a direct link of hazard assessment with risk estimates in urban areas. This is of major interest in most of European countries that allow for a long lasting history on the effects of past earthquakes. Risk is derived using a holistic procedure, a new concept of global damage (the Disruption Index), in which urbanized areas represents a complex network where transportation system, water and wastewater system, building stock, schools, hospitals and security are all taken into account. Major contributions revolve around the following three topics:

1. Investigations for the development of probabilistic hazard assessment.

Analysis of macroseismic fields using statistical data depth functions. Considerations leading to attenuation probabilistic modelling (Agostinelli and Rotondi) deal with the statistical analysis of the shape of macroseismic fields, and Probabilistic modelling of macroseismic attenuation and forecast of damage scenarios (Rotondi et al.) propose a probabilistic modelling of macroseismic attenuation which starts with a clustering procedure to select classes of macroseismic fields (MFs) with similar attenuation trend within

Gaetano Zonno

gaetano.zonno@ingv.it

EERC, Selfoss, Iceland

2 INGV, Milan, Italy

3 IST, Lisbon, Portugal 
a database. Then a probability model for the macroseismic decay is proposed and an estimation method of the probability distribution of the intensity at site is presented in both isotropic and anisotropic cases; finally, observed and estimated intensities at site are compared through three validation criteria. Summarizing, for each of these test areas a macroseismic dataset has been compiled, the probability distribution of the intensity decay at any site has been estimated, given the epicentral intensity, and included in a procedure for hazard assessment based on seismic histories at site, and damage scenarios from observed and synthetic MFs have been estimated. Moreover solutions have been found to specific problems (e.g., completion of MFs of off-shore earthquakes, Application of SASHA to seismic hazard assessment for Portugal Mainland (Carvalho and Albarello) arisen from the application of the above-mentioned methods to the test areas considered in the project (Mt. Etna (Italy), Seismic hazard assessment in the volcanic region of Mt. Etna (Italy): a probabilistic approach by macroseismic data applied to volcano-tectonic seismicity (Azzaro et al.), Portugal and Azores Islands Source and high frequency decay parameters for the Azores region for stochastic finite-fault ground motion simulations (Carvalho et al.), Alicante-Murcia (Spain) Probabilistic seismic hazard assessment in SESpain based on macroseismic site histories (María José Jiménez et al.) and Iceland Seismic hazard assessment for Iceland in terms of macroseismic intensity using a site approach (Vera D'Amico et al.)

\section{Investigations for the development of risk analysis.}

The start point of the risk analysis was dedicated to the calibration of the instrumental data for all the datasets available for each area in order to allow to contribute with its own expertises (knowledge in the fields of waveforms simulations, data analysis, etc.) and to compare results on common data. Ground-motion scenarios on Mt Etna inferred from empirical relations and synthetic simulations (Langer et al.), Ground motion observations and simulation for local earthquakes in the Campi Flegrei volcanic area (Galluzzo et al.) and the short paper Site effects in ground motion simulation for UPStrat-MAFA test areas (Scarfi et al.)

In this Volume we have emphasized two aspects of the seismic risk evaluation. These are vulnerability assessment-as exemplified by the public schools in Lisbon and the residential building stock in Lisbon and Algarve Evolution of earthquake losses in Portuguese residential building stock (Luísa Sousa and Campos Costa) — and the newly introduced concept of the Disruption Index The Disruption Index (DI) as a tool to measure disaster mitigation strategies (Mónica Ferreira et al.). In the first case the seismic risk is obtained Building vulnerability and seismic risk analysis in the urban area of Mt. Etna volcano (Italy) (Salvatore D'Amico et al.) by combining the vulnerability of different building types and the seismic hazard for the site, which are then expressed in terms of the effects of the events derived from an earthquake catalogue that exceed a specified threshold during a given period. The outcome reflects the average seismic risk of the buildings and facilities in question during the period considered. In the second case, a new concept of global disruption measures (Disruption Index) has been introduced to take into account not only the physical damage, but also the functionality interdependencies of urban systems. We use a scenario input that conforms to the earthquake catalogue, but we do not use the entire catalogue (as outlined in the first case) The role of the urban system dysfunction in the assessment of seismic risk in the Mt. Etna area (Italy) (Fabrizio Meroni et al.); Damage to residential buildings in Hveragerði during the 2008 Ölfus Earthquake: 
simulated and surveyed results (Rajesh Rupakhety et al.). Then, for a given scenario that is described in terms of the source location and magnitude, and so on, we associate the estimated damage of the buildings and the critical facilities that result in a spatial series of induced damage. These two methods approach the problem of seismic risk differently, and they provide complementary risk measures.

The spatial interactions between the elements at risk and the hazard are depicted in GIS, by simple map overlaying. This information will be the input for the QuakeIST ${ }^{\circledR}$ seismic scenario simulator. To run the Disruption Index method [QuakeIST ${ }^{\circledR}$ : Earthquake scenario simulator using interdependencies (Mota de Sá et al.). The code QuakeIST ${ }^{\circledR}$ requires very extensive data input in terms of the elements at risk and the hazard information. Additionally, seismic scenario simulations were developed for each study area, for each country, to ensure that the specification robustness, consistency, and implement ability, and to promote interoperability between users.

3. Investigations for the development of disaster-prevention strategies.

Prevention strategies based on education are based on the fact that properly informed on useful actions towards reduction of vulnerability and improvement of building resilience, the citizens can indeed promote political choices that include disaster mitigation. Such information also acts on the likelihood that an at-risk population will take self-protective measures.

In the contributions Education: can a bottom-up strategy help for earthquake disaster prevention? (Gemma Musacchio et al. (a)) and Dissemination strategies to instil a culture of safety on earthquake hazard and risk (Gemma Musacchio et al. (b)) suggest that prevention strategies should encompass the assessment of earthquake impact and adequate actions to reduce the structural vulnerability, and they need to be supported by adequate long-term actions, with emphasis on education. Generally speaking, education is fundamental to enhance the skills for the recognition of dangerous situations, and to address these in a reasonable and sustainable way.

In Musacchio et al. (a) numerous outreach activities carried out in the project for the public and stakeholders, to encourage the development of a bottom-up strategy towards disasters mitigation are described. Here an analysis of compulsory school education in the three European countries participating to the project showed that crucial aspects of risk education concerning natural hazards are starting age, incompleteness of textbooks, and lack of in-depth studies of the students upon completion of their compulsory education cycle. Actions towards kids-education involved hands-on tools, immersive environments, and learn-by-playing approaches. A video game, "Treme-treme", was prepared to motivate, educate, train and communicate earthquake risk to players/students. The game focuses on do's and don'ts for earthquake shaking, and allows children to think about what might be useful in the case of evacuation. Education of the general public was addressed using audio-visual products strongly linked to the social, historical and cultural background of each country. Five videos tackled rising of awareness of seismic hazards in Lisbon, the area surrounding Reykjavik, Naples, and Catania, four urban areas prone to earthquake disasters.

Informal Education for Disaster Risk Reduction (Asthildur Bernhardsdottir et al.) has evaluated the degree to which local authorities were involved in the dissemination of earthquake risk and hazard mitigation information, and specifically how this information was channeled to schools. 
In Musacchio et al. (b) dissemination that highlights research findings and place their outcomes in a context where they can be understood and appreciated, was addressed as an essential duty of the project, especially since outcomes dealt with civil protection aims. We described how we have chosen to convey main tasks and practical outcomes of the project through dedicated channels formal as well as informal, to contributed to the solution of the paradox between the need of information and the lack of thrust in local authorities that are responsible for providing safety.

As Guest Editors of this Special Volume of the Bulletin of Earthquake Engineering, we would like to deeply thank the authors and the international Panel of Reviewers for all contributions who made this publication possible. We would also like to express special thanks to the Editor of BEEE, Prof. Atilla Ansal, for all he support and to the Technical Staff of Springer for the assistance provided. 